Research Article

\title{
The Mechanism of Evolution and Balance for e-Commerce Ecosystem under Blockchain
}

Fengqin ZhuanSun (iD, Jiaojiao Chen, Wenlong Chen, and Yan Sun

School of Management, Wuxi Institute of Technology, Wuxi 214000, China

Correspondence should be addressed to Fengqin ZhuanSun; zhsfq@wxit.edu.cn

Received 15 October 2021; Revised 9 November 2021; Accepted 13 November 2021; Published 13 December 2021

Academic Editor: Hai Dong

Copyright (c) 2021 Fengqin ZhuanSun et al. This is an open access article distributed under the Creative Commons Attribution License, which permits unrestricted use, distribution, and reproduction in any medium, provided the original work is properly cited.

With the development of society, e-commerce competition has become increasingly intense and has ascended to the level of the ecosystem. Therefore, it is extremely significant to study the mechanism of evolution and balance for the e-commerce ecosystem. Simultaneously, blockchain technology is essentially a consensus mechanism, the core idea of which is decentralization, but it is actually the deconstruction of privileges and authority. Especially, the influence on the e-commerce ecosystem cannot be underestimated. Blockchain technology ultimately changes not only technology, but a comprehensive reconstruction of various industries. Building an e-commerce information ecosystem based on blockchain can promote the healthy and sustainable development of e-commerce information ecology. This work combines the definition and technical characteristics of blockchain, discusses the blockchain-based e-commerce information ecosystem model, and discusses how to achieve the ecological balance and system evolution of e-commerce under the background of blockchain. According to the internal problems of the e-commerce ecosystem, three evolutionary paths are proposed in this work. First, consider the timeliness of the information and construct a full-process information channel. Second, remove central nodes and build a safe and efficient block payment. Third, solve the blind zone in the field of logistics and create efficient and transparent intelligent logistics. This work can provide an effective reference for the development of e-commerce.

\section{Introduction}

With the development of society, the Internet has ushered in a brand-new business era and the era of e-commerce. e-Commerce can be regarded as another industrial revolution after the agricultural revolution and the industrial revolution. It has become the business trend of the 21 st century and an important means to promote economic development and management progress [1-6].

With the rapid development of e-commerce, it is imperative to build a balanced and sustainable e-commerce information ecosystem. At the same time, the emergence of digital currency represented by Bitcoin, the underlying technology of the digital cryptocurrency system, and the blockchain has also attracted widespread attention from the academic community [7-12]. Blockchain technology is regarded as another disruptive technological innovation in the computing paradigm after the Internet. The application of blockchain technology has gradually penetrated into many fields such as network financial services, the Internet of Things, online education industry, and network sharing economy. Its rapid development is expected to lead the transformation of the Internet economy from an application-driven innovation model to a technology-driven innovation model. Blockchain technology is a complete, distributed, and nontamperable ledger database technology maintained by a multicenter consensus. It is ordered data composed of distributed storage, decentralization, cryptography, consensus mechanism, and smart contracts. The overall characteristics of blockchain and blockchain technology are embodied in the immutability of data, collective maintenance of data, and multicentralized decision-making. 
The business ecosystem refers to the interaction between individuals and organizations [13-16], whose members include core enterprises, consumers, market intermediaries, suppliers, and risk-takers. The internal members of the system constitute a value chain, and different value chains are intertwined. As a significant value network, each subject in the system has its own function and at the same time is interdependent. Material, energy, and information flow and circulate among alliance members through a specific value network. The importance of e-commerce in the process of economic development continues to increase, and the research of e-commerce ecosystem has gradually become a hot spot. The e-commerce ecosystem mainly includes e-commerce platforms, merchants, consumers, suppliers, logistics companies, third-party payment companies, drainage companies, consumer finance, supply chain finance, and these organic enterprises and individuals within the system, i.e., internal system. The information flow, capital flow, and logistics generated by the communication between living organisms together constitute the e-commerce ecosystem. The e-commerce ecosystem is characterized by diversification and complexity [17-19]. Most of the professional e-commerce companies prefer using a cooperative model to achieve the value creation [20]. The imperfect coordination mechanism between the subjects of the e-commerce ecosystem has led to problems, such as the lack of online transaction data between consumers and merchants [21], and the obvious lack of coordination between e-commerce and logistics [22].

As a dynamic and open business ecosystem, the e-commerce ecosystem always exchanges energy and material with the external environment. The external environment is the basis for the existence of the e-commerce ecosystem. There are also interactions between different subjects within the e-commerce ecosystem. The specific manifestation is the flow of information flow, capital flow, and logistics in the entire e-commerce ecosystem. Information flow, capital flow, and logistics are the core of the e-commerce ecosystem. In order to study the utility of information flow, capital flow, and logistics in the entire e-commerce ecosystem, the subjects in e-commerce are divided into different populations, and the e-commerce system is explained by studying the interaction between different populations and different subjects for evolution and balance mechanism. The main research method is synergetics in evolutionary economics, and it is used to study the collaboration within the e-commerce ecosystem to achieve the balance of the system.

The contribution of this work can be summarized as follows: according to the internal problems of the e-commerce ecosystem, three evolutionary paths are proposed in this work: (1) consider the timeliness of the information, and construct a full-process information channel. (2) Remove central nodes, and build a safe and efficient block payment. (3) Solve the blind zone in the field of logistics, and create efficient and transparent intelligent logistics. This work can provide an effective reference for the development of e-commerce.

\section{Related Work}

Looking at the foreign literature, the application research based on blockchain technology shows that a hundred flowers bloom and a hundred schools of thought are contending. As far as the field of e-commerce is concerned, the research of blockchain focuses on the innovation of specific things in e-commerce. The evolution and balance mechanism of the e-commerce ecosystem in the context of blockchain is a new topic that needs to be studied urgently. Bilgihan and Gen [23] analyzed the importance of e-commerce companies maintaining a good reputation from the perspective of consumers. Trust is the prerequisite for consumers to maintain online shopping loyalty. Yu et al. [24] believed that e-commerce business processes adopt a structure of multiple participants, including shopping customers, merchants, third-party payment platforms, and banks. The communication between these participants relies on web services and application programming interfaces. The complex interactions between multiple participants will bring new security challenges. Min [25] thought that the blockchain was considered to be a peer-to-peer information network technology. The use of distributed account books to store digital asset transaction records can reduce the intervention of intermediaries, reduce external risks, and improve the flexibility of supply chain management. Robert et al. [26] believed that information will be in the process of transforming new energy for enterprise development to an open innovation ecosystem, and it is necessary to ensure that data owners can better control their own data and privacy and independently choose whether to share and with whom to share and exchange specific data streams, as well as regions. The degree to which blockchain technology meets these requirements. Angelis and Ribeiro da Silva [27] discussed the relationship between the characteristics of blockchain technology and its potential value drivers. The value drivers of blockchain are mainly reflected in transactions, smart contracts, and distributed applications. These studies have discussed issues such as information asymmetry, information security, supply chain management, user privacy, and information sharing in e-commerce companies, and we believe that the application of blockchain technology is conducive to solving the above problems. The above studies all study the impact of blockchain technology on e-commerce from a single perspective, but there is a lack of research on the evolutionary impact of blockchain on the e-commerce ecosystem from a systematic perspective. Dennis and Owenson [28] constructed a platform merchant credit rating system based on blockchain technology, which eliminates the inauthenticity of online rating information. Schaub et al. [29] further expanded the application of blockchain in the credit rating system of merchants, realizing real online reviews of merchants under the condition of high privacy of buyer information.

Different from the foreign research studies, the domestic research of e-commerce ecosystem is mainly concentrated in the fields of financial currency, medical care, sharing economy, education, and energy. Wang [30] discussed the feasibility of blockchain currency as legal tender. Zhang [31] 
cited the case of Philips Medical to illustrate that blockchain technology could realize the authentication and privacy protection of patient medical records. Li et al. [32] realized distributed learning record storage and credit banking services by the blockchain technology. Zhang et al. [33] studied the typical application of blockchain technology in the energy Internet. Based on the consensus mechanism of the blockchain and the core idea of decentralization, Dan [34] launched the analysis of the reconstruction of the e-commerce ecosystem by the blockchain. Zhang and Li [35] discussed the electronic commerce in the context of the blockchain. The collection of business value-added tax has been explored, and the conclusion that blockchain is universal in the collection of e-commerce value-added tax has been arrived, and relevant suggestions have been given. Chen [36] conducted research on the corporate credit information sharing model based on the blockchain technology, aiming at China's corporate credit information industry being in the primary stage of development, and the credit coverage rate of the credit reporting system is not high, especially the lack of credit information for small and micro-enterprises. It is difficult for small and micro-enterprises to raise funds and propose a proposal to build a corporate credit information sharing model based on blockchain technology. Liu [37] from the perspective of ecology used business ecosystem theory, evolutionary economics, and evolutionary games theory, and the theory and methods of ecology and collaborative evolution were introduced into the field of cross-border e-commerce research, and a platform-based cross-border e-commerce ecosystem is proposed and constructed. Zhang et al. [38] researched by building an e-commerce ecosystem user perception model. It was believed that the factors that affect user perception can be divided into three categories: self-organization factors, internal relationship factors, and health factors, and they have different degrees of influence on the online shopping experience.

\section{Analysis between Blockchain and E-Commerce Ecosystem}

In this section, the relationship between blockchain and e-commerce ecosystem will be dissected from two aspects: the fit between blockchain and e-commerce as well as the e-commerce information ecological model based on blockchain.

\subsection{Analysis of the Fit between Blockchain and E-Commerce}

3.1.1. Sharing Mechanism Fits. Blockchain technology is a distributed shared database technology. All nodes in the network share data and information, and each node stores a complete account book. This method is different from the traditional centralized network structure. The data information in the blockchain network is mutually backed up between different nodes, and the data update and maintenance are completed by multiple nodes in the system. e-Commerce is a new networked economic activity in which suppliers, distributors, customers, e-commerce platforms, third-party payment, logistics companies, and other entities realize resource sharing through information sharing. Blockchain technology and distributed management of e-commerce information resources are both based on the development concept of information sharing, relying on the data network development space to engage in various operations such as data exchange, transfer, and storage. From this, it can be seen that the two have a consistent relationship in the information sharing mechanism, as shown in Figure 1.

3.1.2. Trust Mechanism Fits. The blockchain network has a high degree of trust. Compared with the traditional trust mechanism, its trust is built on technical endorsement, not a centralized credit institution. This mechanism ensures that the data interaction between distributed nodes can be carried out without mutual trust and trust guarantees from central institutions. It can be seen that there is a close relationship between the two in the trust mechanism, as shown in Figure 2.

3.1.3. Coordination Mechanism Fits. The information verification, exchange, update, and maintenance of the blockchain database are completed by the cooperation of distributed nodes. Relying on the network service platform, e-commerce optimizes the cooperative relationship among suppliers, logistics, distributors, customers, financial payment institutions, and the government to ensure the smooth flow of information among various entities. It can be seen that the two have a coherent relationship in the coordination mechanism, as shown in Figure 3.

3.1.4. Security Mechanism Fits. The internal data structure of the blockchain network has the characteristics of security, transparency, nontampering, and traceability. Its distributed redundant storage mode means high data security, which is beneficial to avoid large-scale data loss due to the collapse of the central organization. E-Commerce data security involves website information security, transaction information security, and user information security. The blockchain data security mechanism helps to enhance the construction of an e-commerce information security protection system. It can be seen that the two have a close relationship in the security mechanism, as shown in Figure 4.

3.1.5. Contract Mechanism Fits. The blockchain system has a complete smart contract function. The intelligent contract built into the block can be run in the virtual machine environment of the blockchain after being compiled. Therefore, once an event triggers the execution conditions premade by the state machine, the system will automatically execute the contract. e-Commerce uses smart contracts to replace operating, transaction, and legal terms, which can not only ensure the automatic execution of system rules, but also avoid malicious interference caused by human factors, improve execution efficiency, and reduce resource waste. It 


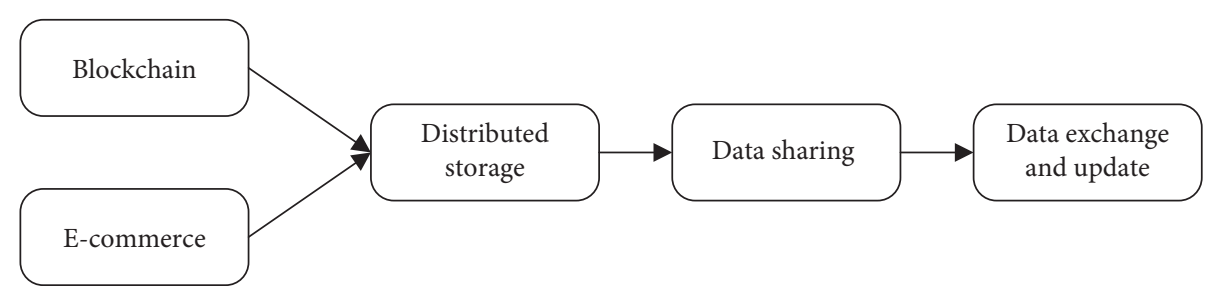

FIGURE 1: Sharing mechanism fits.

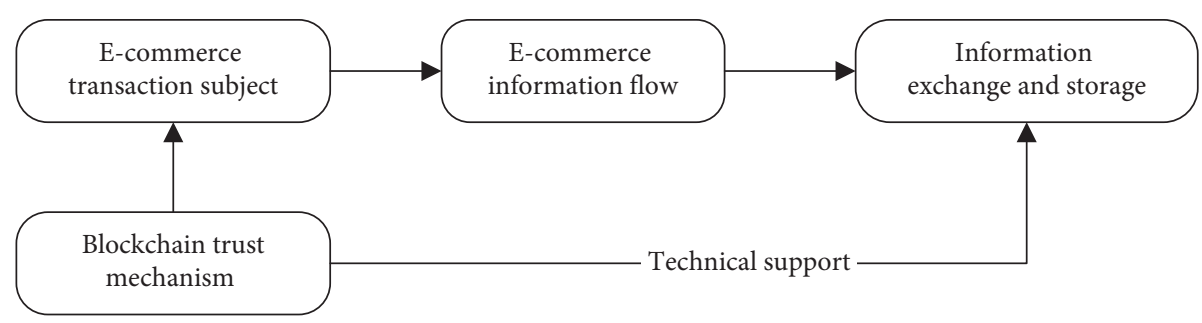

FIgURE 2: Trust mechanism fits.

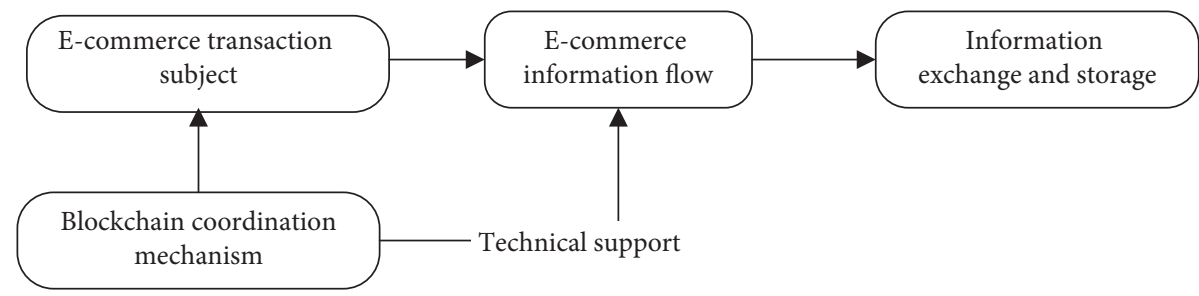

Figure 3: Coordination mechanism fits.

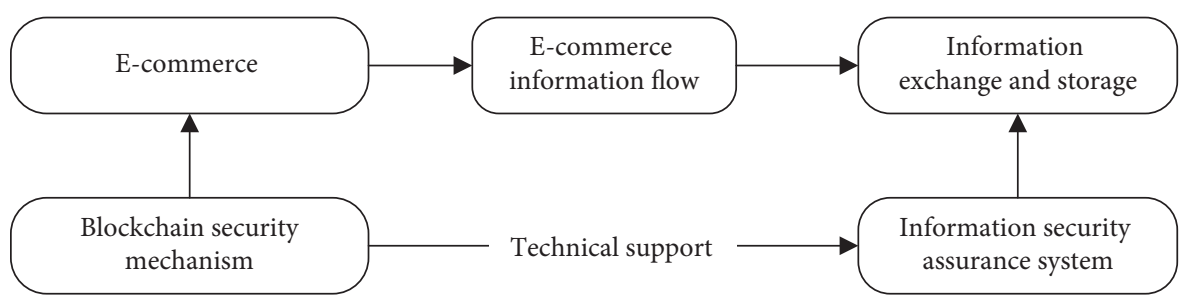

FIGURE 4: Security mechanism fits.

can be seen that the two have a close relationship in the contract mechanism, as shown in Figure 5.

\subsection{E-Commerce Information Ecological Model Based on Blockchain}

3.2.1. E-Commerce Information Ecological Chain. In the Internet business environment, the e-commerce information ecological chain is an important content to ensure the high-speed circulation of online business information. It is mainly based on information technology, combined with information sharing and main body collaboration, and in accordance with the actual development of the enterprise itself and its respective functional characteristics, a network structure that maximizes the benefits of the enterprise while obtaining valuable information to achieve gains. E-Commerce information ecological chain is mainly composed of information, information transmitter, information environment, and information technology. Among them, information is the foundation, the information transmitter is the core, the information environment is the medium for information circulation, and information technology is the support for operation, which provides technical guarantee for realizing the high-speed circulation of information and ensuring the information security of e-commerce websites.

Information subjects in the e-commerce information ecological chain play different roles in real life. They are not only information producers, but also information transmitters and consumers. They transform and depend on each other between different roles. In the information flow of the entire ecological chain, the information producer is the starting point (suppliers, merchants), and its main job is to provide information and collect information. In the ecological chain, the information transmitter (certification center, credit agency) is an internal link, and the main work is to transmit and process information, and to process and arrange information. Consumers are the end of the 


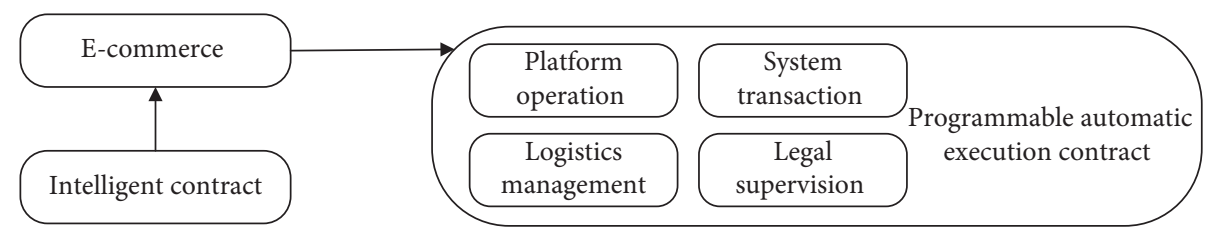

Figure 5: Contract mechanism fits.

information flow of the ecological chain, which mainly include website managers and customers. Information decomposers (government, scientific research institutions) mainly filter and feedback information. In the ecological chain, various subjects will interact and cooperate to achieve healthy competition and mutual benefit and win-win, make the development environment of the ecological chain more harmonious, and maintain the balance of the information ecology to a certain extent.

During the normal operation of the e-commerce information ecological chain, the main body will not only exchange certain information, but also maintain communication with the external environment, realize information exchange and energy exchange, and will also be affected by the ecological environment and the information environment. Therefore, it is necessary to continuously coordinate the various internal elements to achieve coordinated development and allow them to form a relatively stable self-regulation mechanism.

According to the decentralized characteristics of the blockchain, the blockchain is used as the lowest technology in the e-commerce ecological chain. It can be known that the main basic models are divided into data layer, virtual network layer, core consensus layer, value incentive layer, intelligent contract layer, and real-world applications. Among them, the data layer includes network and chain structures such as information flow and logistics, as well as technologies such as time stamps. Connect the blocks in the corresponding chronological order to form the main chain. Through the use of timestamps, encryption technology, the goals of data security, and traceability can be achieved. Designing P2P networking methods, verification protocols, and related verification mechanisms in the virtual network layer can make the status of each information block equal and form a flat topology structure, so that the connection between blocks can be realized without hindrance when a new block is formed, the whole network broadcast method can be used to enable each node to undertake the corresponding obligations of spreading and verifying the new block. The decentralized structure makes the degree of information sharing between information subjects continue to increase, so that the flow of information, logistics, and capital will not be interrupted due to the damage of some nodes, and the value of information has been increased. With the help of platform sharing in the block, the final ecological value stream can be formed. The blockchain-based e-commerce information ecological chain is shown in Figure 6.

3.2.2. E-Commerce Information Ecosystem. The dynamic interactive relationship between information subjects and the information environment, using information as a link, is called the e-commerce information ecosystem. In this type of ecosystem, it mainly focuses on e-commerce companies, sellers, customers, and other information subjects to carry out related e-commerce activities. The information ecosystem is divided into five levels: core, technology, media, extension, and periphery.

In the e-commerce information ecosystem, the core layer includes e-commerce companies, sellers, and customers. The technical layer includes blockchain-based seller-customer interaction software, product recommendation system, and online evaluation system. The media layer includes thirdparty payment, logistics companies, advertising companies, search websites, and other service providers. The extension layer includes government, scientific research, and educational institutions. The outer layer includes political, social, cultural, legal, economic, and other environments. The e-commerce information ecosystem constructed by blockchain technology is shown in Figure 7.

\subsubsection{E-Commerce Information Ecosystem Model Based on} Blockchain. Based on the abovementioned research on the blockchain-based e-commerce information ecological chain and the blockchain-based e-commerce information ecosystem, this part proposes the theoretical framework of the blockchain-based e-commerce information ecosystem model. It has ecological characteristics such as data sharing, transparency, antitampering, open data platform, consensus and collaboration of various subjects, dynamic intelligent evolution, and value appreciation, which can promote the stable, sustainable, and healthy development of e-commerce information ecosystem. The e-commerce information ecosystem model based on blockchain is shown in Figure 8 .

In traditional e-commerce, the supervision of the e-commerce platform population and the complaints of the consumer population are mainly used to ensure the integrity of the business [39]. Consumers in e-commerce under the blockchain can use the product traceability mechanism to detect the validity of the product, generate full trust in the information of the purchased product, and then trust in the merchant and e-commerce platform. This kind of strong endorsement of credit relies on data precipitation. It is a completely different model from traditional e-commerce companies relying on their own reputation and volume to gain consumer trust. What e-commerce merchants under the blockchain need to pay attention to is no longer consumer trust issues, but consumer preferences and product quality, not to mention worrying about the opportunistic behavior of other businesses. The regulatory pressure on e-commerce platforms under the blockchain will be greatly reduced, and the reputation of e-commerce platforms will 


\begin{tabular}{|c|}
\hline Application layer \\
\hline Intelligent contract layer \\
\hline Value incentive layer \\
\hline Core consensus layer \\
\hline Virtual network layer \\
\hline Basic data layer \\
\hline
\end{tabular}

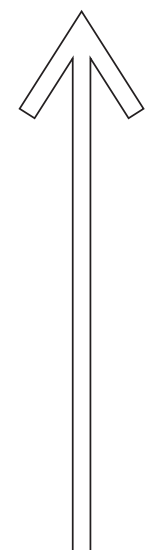

FIgURE 6: E-Commerce information ecological chain.

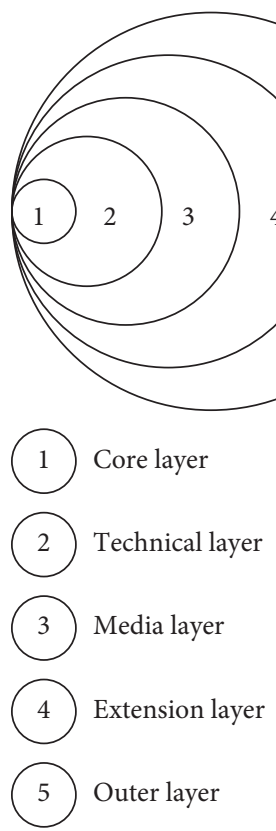

Figure 7: The e-commerce information ecosystem based on blockchain.

increase. Compared with traditional e-commerce, the amount of data storage can be significantly reduced, and the cost of data maintenance will also be reduced, which can reduce the e-commerce of the entry barrier of the platform and the improvement of the operating efficiency of the e-commerce platform. The current monopoly of e-commerce platforms under the blockchain will be broken. The e-commerce market is highly dynamic, consumers are less sticky, merchant transfer costs are gradually reduced, and platform market share is unstable [40].

The relative advantages of traditional e-commerce platforms under the blockchain have been greatly reduced, and the lowering of the barriers to entry will lead to more emerging e-commerce platforms joining the e-commerce ecosystem. Consumers have more diversified platform choices and traditional e-commerce platforms. Business platforms may face more challenges from emerging

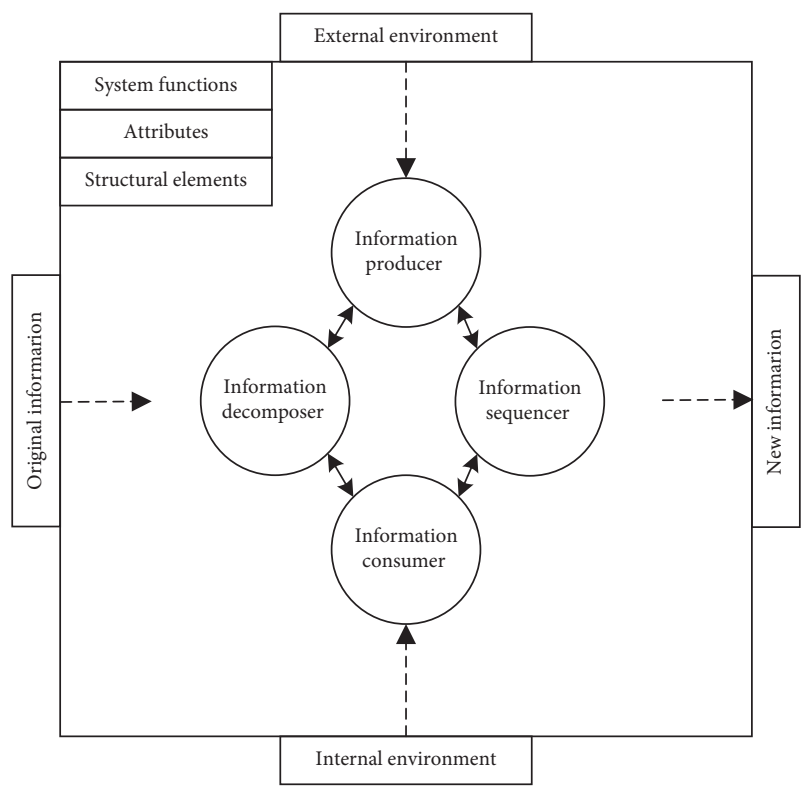

FIGURE 8: The e-commerce information ecosystem model based on blockchain.

e-commerce platforms. Traditional e-commerce platforms that refuse to use new technologies based on vested interests will be gradually eliminated. The challenges of new platforms will also inject more vitality into the e-commerce ecosystem and eventually form a model of multiplatform coexistence and healthy competition.

\section{Evolution Path for E-Commerce Ecosystem under Blockchain}

Through the comparative analysis of the e-commerce ecology combined with the blockchain technology and the traditional e-commerce ecology, in order to make better use of the technological advantages of the blockchain to develop e-commerce and solve the problems in the traditional e-commerce ecology, the blockchain is proposed. There are three evolutionary paths of e-commerce ecology, which are discussed next.

4.1. Construct Full-Process Information Channel. The asymmetry of information among various subjects is the main problem that affects the ecological balance of e-commerce. To promote the further development of the e-commerce ecosystem, it is necessary to ensure that the internal information of the system is open, transparent, and effective. In the case of using blockchain technology to build an information system, distributed storage technology reduces the amount of consumer information storage for e-commerce companies and reduces corporate consumption costs. The data on the blockchain is jointly participated and shared by all accounting nodes. Maintenance, transparent and open to all parties, data recording, and storage no longer rely solely on the central node, and all business participants in the transaction can participate in decision-making, master their own data, ensure consumer information security, and 
avoid consumer information being compromised. The commodity information on the e-commerce platform can be encrypted by cryptography on the chain. The hash algorithm makes it very difficult to tamper with the information, and the data changes can be quickly identified through the Merkle tree structure, so it can effectively prevent the tampering of the information on the chain. At the same time, distributed storage and consensus algorithms can ensure that the modification of a single point is invalid. Only more than half of the computing power can modify the information on the chain. All information on the chain will be time stamped, and every information change will be recorded. In this case, the information on the chain can be traced to the source, which solves the problem of information asymmetry in the e-commerce ecosystem.

Each node on the blockchain is peer-to-peer and can directly interact. A node can interact with multiple nodes at the same time. Overcome the shortcomings of traditional electronic data transmission, and realize the efficient collaboration of business participants on the blockchain. The information communication system includes suppliers, connects consumers and suppliers, and realizes the communication of commodity information. Consumers can interact with enterprises through the network platform, participate in the product design, production and consumption of enterprises, and customize personalized products. The role of consumers is gradually transformed into a cocreator of value, which is conducive to satisfying consumer needs and improving consumer loyalty [41]. Make full use of the traceability and nontampering characteristics of blockchain data to ensure the authenticity and effectiveness of the communication information, ensure the symmetry of the information between the two parties, and combine the omni-channel information communication system to strengthen the trust and understanding of all parties in the e-commerce ecosystem. Lay the foundation for further in-depth cooperation.

4.2. Build Safe and Efficient Block Payment. The reason why the payment link of traditional e-commerce requires a third-party payment company to transfer is because both parties to the transaction need a third-party institution to endorse the transaction to solve the problem of mutual trust in the transaction. The e-commerce ecology embedded in the blockchain can ensure the authenticity, effectiveness, and traceability of information, transforming from the past information transmission to value transmission, and from the original information Internet to the value Internet.

In this case, the information on the blockchain can be deposited as a strong credit endorsement; instead of relying on traditional third-party institutions, the central node of transactions can be removed and the existing credit system can be reconstructed. In the transaction link of e-commerce, it is based on the consensus mechanism to ensure that all parties to the transaction confirm the transaction information, and the transaction funds pass the third-party payment company to circulate directly among the transaction subjects, and it can solve the cumbersome payment process, high management costs, and funds in the existing e-commerce backlogs, and other issues have improved the efficiency of the use of funds in the e-commerce ecosystem. Use the strong credit endorsement formed by the precipitation of e-commerce data under the blockchain to improve the construction of the e-commerce credit system, and rely on the historical transaction information of e-commerce enterprises to conduct credit ratings for enterprises and the e-commerce platform to jointly finance corporate banks and other financial institutions. Use the blockchain to build the core of financial supervision tools, carry out deposit certificates and risk monitoring of financial information, and achieve controllable risks in supply chain finance.

Through blockchain transaction accounting and distributed ledger, the problem of reconciliation and settlement costs between financial institutions is solved, combined with digital currency to achieve real-time settlement and improve the operational efficiency of financial institutions. Combining currency and blockchain technology, using blockchain as the underlying technology, realizes the directional circulation, transaction, and settlement of currency, controls the entire life cycle of the currency, and ensures the reasonable and legal use of funds. Embedded in the blockchain, the authenticity and traceability of information transforms the e-commerce information flow into a value stream, and the data are deposited as a strong endorsement of credit, reconstruct the credit system of the e-commerce ecosystem, and realize the financing of funds without the central node.

4.3. Create Efficient and Transparent Intelligent Logistics. Combining the blockchain technology with the Internet of Things, the blockchain does not need to set up a central server, which can avoid expensive operation and maintenance costs, and reduce the use cost of logistics enterprises to apply Internet of Things technology to the logistics field. The cryptographic algorithm and consensus mechanism of the blockchain itself can prevent malicious nodes from accessing the Internet of Things, lower the barriers to entry, and incorporate more logistics products into the chain management. The data on the blockchain are a kind of chain-type data. The logistics information of the goods can be all on the chain, which can realize the accurate traceability of the origin of the goods, the storage of the goods, and the realtime disclosure of the transportation routes. The logistics information is completely transparent to logistics stakeholders and can be integrated in the logistics supply chain, break the status of information islands in the logistics operation process, promote the horizontal flow of logistics information and multiparty collaboration, achieve the purpose of information sharing and in-depth cooperation between all parties in the logistics supply chain, improve logistics efficiency, and integrate areas; the blockchain has become a new breakthrough in the upgrading and transformation of the logistics supply chain. Combining blockchain technology with big data and cloud computing, the distributed storage of blockchain increases the analyzable 
data of logistics enterprises. The filtering and screening of big data improves the availability of data, and cloud computing improves logistics enterprises' data processing capability and intelligent operation level, which will eventually build a transparent and efficient intelligent logistics system.

\section{Conclusions}

This work takes the e-commerce ecosystem as the research object and uses synergetics in evolutionary economics to analyze the interaction between various groups in the e-commerce ecosystem and within the core population. Mainly relying on the three main lines of information flow, logistics, and capital flow, the internal mechanism of the e-commerce ecosystem was excavated, and the imbalance and instability in the e-commerce ecosystem were discovered, and the problems that affected the further development of e-commerce were addressed. The technical characteristics of the blockchain propose three evolution paths of the e-commerce ecosystem to promote the further development of e-commerce. This work mainly analyzes and studies the impact of blockchain technology on the e-commerce ecosystem, but the blockchain technology itself is not yet fully mature, and some problems need to be overcome in the application. All records reached by traditional consensus require more than half of the amount of calculation to be recognized. This requires a lot of time, which affects the performance and efficiency of the blockchain. The full storage of all nodes ensures the validity of the data, but also leads to the problem of large amount of data storage and fast increase of calculation amount. The decisionmaking of multiple parties to participate in the transaction ensures the security of the transaction and also creates the problem of blockchain congestion. Different blockchains cannot achieve cross-chain collaboration due to different protocols. These problems have a great impact on the application of blockchain technology and require in-depth research by scientific researchers to find suitable solutions.

\section{Data Availability}

The datasets used are available from the corresponding author on reasonable request.

\section{Conflicts of Interest}

The authors declare that they have no conflicts of interest.

\section{References}

[1] S. Zheng and Q. Lv, "The evolution of E-commerce in twenty years in China," Journal of Business Economics, vol. 11, no. 265 , pp. 5-16, 2013.

[2] S. Piggott, "Internet commerce and knowledge management-the next megatrends," Business Information Review, vol. 14, no. 4, pp. 169-172, 1997.

[3] P. Levikangas and R. Rni, "From business models to value networks and business ecosystems-what does it mean for the economics and governance of the transport system?" Utilities Policy, vol. 64, 2020.

[4] M. Meyer, J. Utterback, and M. James, "The product family and the dynamics of core capability," MIT Sloan Management Review, vol. 34, pp. 77-92, 1992.

[5] V. S. Veenstra, J. I. M. Halman, and J. T. Voordijk, “A methodology for developing product platforms in the specific setting of the housebuilding industry," Research in Engineering Design, vol. 17, no. 3, pp. 157-173, 2006.

[6] J. Pei, "Solving the problem of charging and discharging of electric vehicles based on particle swarm algorithm," in Proceedings of the International Conference on Information Systems and Computer Aided Education, pp. 534-538, Dalian, China, September 2019.

[7] J. Liu, C. Sun, and Y. Yuan, "Blockchain hotspot field and frontier path in China: based on CiteSpace measurement analysis," Journal of Chongqing University of Posts and Telecommunications, vol. 32, no. 6, pp. 121-129, 2020.

[8] J.-C. Rochet and J. Tirole, "Platform competition in two-sided markets," Journal of the European Economic Association, vol. 1, no. 4, pp. 990-1029, 2003.

[9] S. Muegge, "Business ecosystems as institutions of participation: a systems perspective on community-developed platforms," Technology Innovation Management Review, vol. 27, no. 4, 2011.

[10] L. Metso and M. Kans, "An ecosystem perspective on asset management information," Management Systems in Production Engineering, vol. 25, no. 3, 2017.

[11] J. Pei, "Big data mining in the control of epidemic," Basic and Clinical Pharmacology and Toxicology, vol. 126, pp. 428-430, 2020.

[12] R. Normann and R. Ramirez, "From value chain to value constellation: designing interactive strategy," Harvard Business Review, vol. 7, no. 4, pp. 65-77, 1993.

[13] J. F. Moore, "Predators and prey: a new ecology of competition," Harvard Business Review, vol. 71, no. 3, pp. 75-86, 1993.

[14] J. Sviokla, "Expert systems and their impact on the firm: the effects of planpower use on the information-processing capacity of the financial collaborative," in Proceedings of the Twenty-Second Annual Hawaii International Conference on System Sciences, Kailua-Kona, HI, USA, January 1989.

[15] E. Gummesson and C. Mele, "Marketing as value Co-creation through network interaction and resource integration," Journal of Business Market Management, vol. 4, no. 4, pp. 181-198, 2010.

[16] N. S. P. Tay and R. F. Lusch, "A preliminary test of hunt's general theory of competition: using artificial adaptive agents to study complex and ill-defined environments," Journal of Business Research, vol. 58, no. 9, pp. 1155-1168, 2005.

[17] H. Zhang and Z. Xu, "Research on the structure and evolution of cross-border E-commerce ecosystem based on the perspective of symbiosis," Journal of Social Sciences, vol. 19, no. 928, pp. 44-46, 2020.

[18] J. Pei, J. Li, and B. Zhou, "A recommendation algorithm about choosing travel means for urban residents in intelligent traffic system," in Proceedings of the IEEE Advanced Information Technology, Electronic and Automation Control Conference, pp. 2553-2556, Chongqing, China, March 2021.

[19] A. Gawer and M. Cusumano, How Companies Become Platform Leaders, MIT Sloan Management Review, Cambridge, UK, 2008. 
[20] S. Mei and J. Xu, "Research on collaborative B2B E-business model and value creation," Journal of Management Science in China, vol. 16, no. 5, pp. 55-68, 2013.

[21] X. Wang, Research on the Internal Coordination Mechanism of E-Commerce Ecosystem Based on Evolutionary Game, Tianjin University of Science and Technology, Tianjin, China, 2019.

[22] Y. Zhang, "Blockchain to lead to new changes in E-commerce," Contemporary Economic Management, vol. 39, no. 10, 2017.

[23] A. Bilgihan and Y. Gen, "Customer loyalty in online shopping: an integrated model of trust, user experience and branding," Computers in Human Behavior, vol. 61, pp. 103-113, 2016.

[24] W. Yu, Z. Ding, L. Liu, X. Wang, and R. D. Crossley, "Petri net-based methods for analyzing structural security in E-commerce business processes," Future Generation Computer Systems, vol. 109, pp. 611-620, 2020.

[25] H. Min, "Blockchain technology for enhancing supply chain resilience," Business Horizons, vol. 62, no. 1, pp. 35-45, 2019.

[26] J. Robert, S. Kubler, and S. Ghatpande, "Enhanced lightning network (off-chain)-based micropayment in IoT ecosystems," Future Generation Computer Systems, vol. 112, pp. 283-296, 2020.

[27] J. Angelis and E. Ribeiro da Silva, "Blockchain adoption: a value driver perspective," Business Horizons, vol. 62, no. 3 , pp. 307-314, 2019.

[28] R. Dennis and G. Owenson, "Rep on the roll: a peer to peer reputation system based on a rolling blockchain," International Journal of Digital Society, vol. 7, no. 1, pp. 1123-1134, 2016.

[29] A. Schaub, R. Bazin, O. Hasan, and L. Brunie, "A t privacypreserving reputation system," in Proceedings of the IFIP International Conference on ICT Systems Security and Privacy Protection, pp. 398-411, Ghent, Belgium, May 2016.

[30] S. Wang, "Research on blockchain of legal tender system," Economist, vol. 0, no. 9, pp. 77-85, 2016.

[31] B. Zhang, "The application of foreign blockchain technology and related enlightenment," Financial Technology Time, vol. 24, no. 5, pp. 35-38, 2016.

[32] Q. Li and X. Zhang, "Blockchain: a technology to win open and trust in education," The Journal of Distance Education, vol. 35, no. 1, pp. 36-44, 2017.

[33] N. Zhang, Y. Wang, C. Kang, J. Cheng, and D. He, "Blockchain technique in the energy Internet: preliminary research framework and typical applications," Proceedings of the CSEE, vol. 36, no. 15, pp. 4011-4022, 2016.

[34] M. Dan, "Analysis of blockchain technology's reconstruction of E-commerce ecosystem," Chinese Commerce, vol. 14, pp. 26-27, 2020.

[35] T. Zhang and B. Li, "Analysis of the value-added tax collection of E-commerce model under the background of blockchain," Chinese Commerce, vol. 14, pp. 28-29, 2020.

[36] Y. Chen, Research on Enterprise Credit Information Sharing Model Based on Blockchain Technology, Zhejiang University of Finance \& Economics, Hangzhou, China, 2019.

[37] J. Liu, Research on Cooperative Evolution of Cross-Border E-Commerce Ecosystem, Changchun University of Technology, Changchun, China, 2018.

[38] L. Zhang, Z. Li, and J. Wang, "User perception model of E-business ecosystem," Information Science, vol. 38, no. 8, 2020.

[39] L. Zhang, X. Wang, and J. Li, "Dynamic evolutionary game of credit mechanism among core populations in E-commerce ecosystem," Operations Research Management Science, vol. 29, no. 4, pp. 93-101, 2020.
[40] T. Wu and Z. Zhao, "Anti-monopoly law on the "choose one from two" action of E-commerce platform: on the insufficient application of the theory of abuse of superior bargaining position," Journal of Chongqing University of Posts and Telecommunications, vol. 32, no. 6, pp. 59-68, 2020.

[41] H. Guo, "Internet enterprise data identification antitrust legal supervision regulation," Journal of Chongqing University of Posts and Telecommunications, vol. 31, no. 2, pp. 37-46, 2019. 